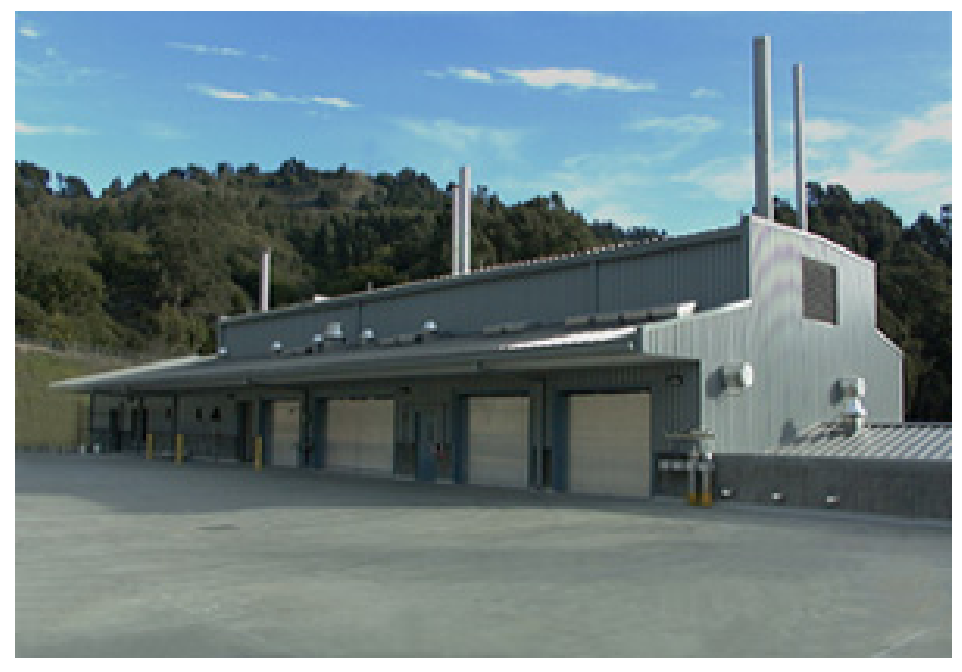

\title{
Waste Management Quality Assurance Plan
}

\author{
Waste Management Group \\ Environment, Health and Safety Division \\ Ernest Orlando Lawrence \\ Berkeley National Laboratory
}

Revision 6

Effective Date: August 14, 2006

Prepared for the U.S. Department of Energy under Contract No. DE-AC02-05CH11231 


\title{
Waste Management Quality Assurance Plan
}

\author{
LBNL/PUB-5352 \\ Revision 6
}

Effective Date: August 14, 2006

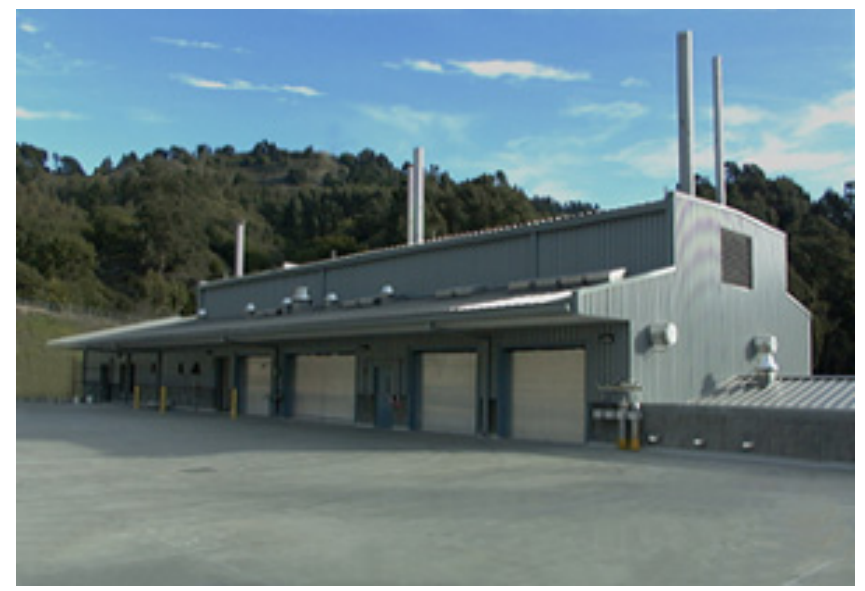

Approved By:

Nancy E. Rothermich

Waste Management Group Leader

Environment, Health and Safety Division

Approved By:

Howard Hatayama

Acting Division Director

Environment, Health and Safety Division

Ernest Orlando Lawrence Berkeley National Laboratory 


\section{Contents}

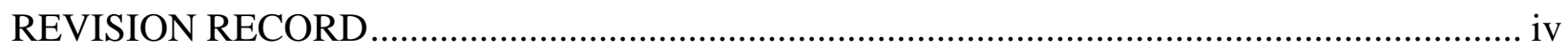

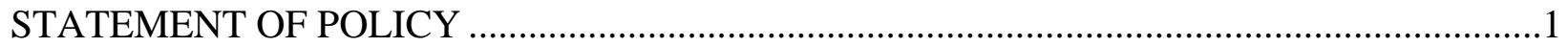

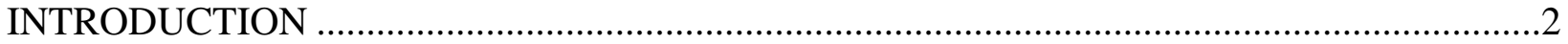

1.0 PROGRAM

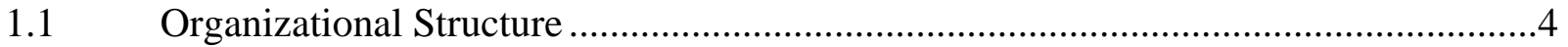

$1.2 \quad$ Management Quality Assurance Functions …….........................................................

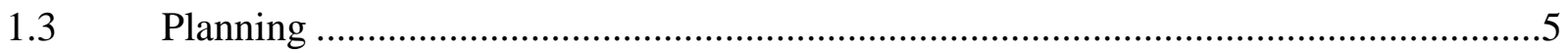

2.0 PERSONNEL TRAINING AND QUALIFICATION .....................................................6

$2.1 \quad$ Orientation, Training, and Evaluation of Personnel .....................................................

$2.2 \quad$ Orientation and Training of Waste Generators ..........................................................

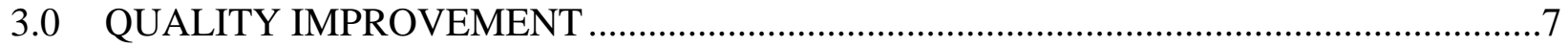

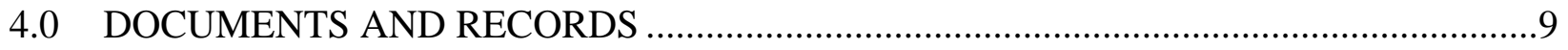

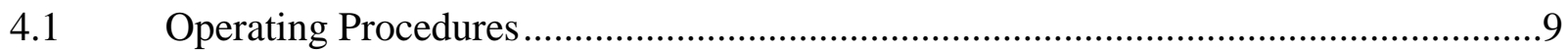

4.1.1 Preparation of Written Procedures, Work Plans, Instructions and Reports...............9

4.1.2 Procedure Review and Revision Process ............................................................10

4.1.3 Control of Formal Procedures and Documentation Binder ......................................10

4.2 Operating and Programmatic Records ………......................................................

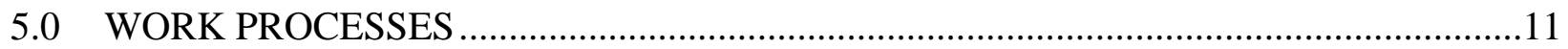

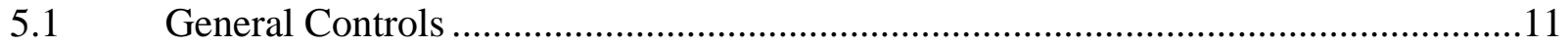

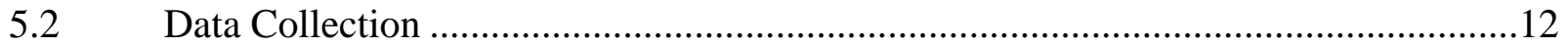

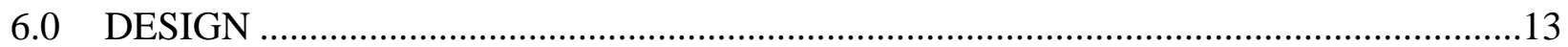

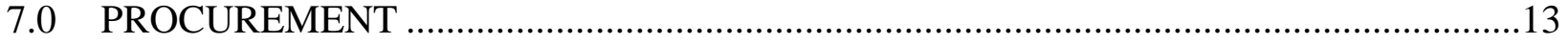

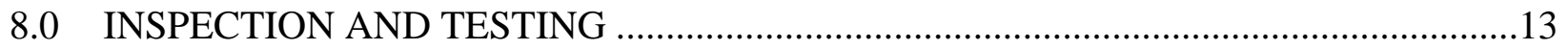

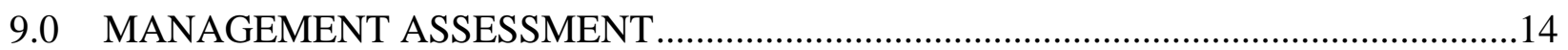

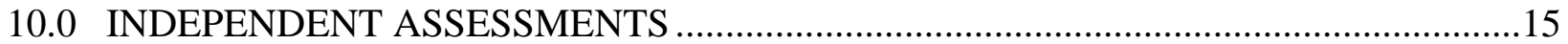




\section{Revision Record}

\begin{tabular}{|c|c|c|}
\hline Rev. No. & Date & Description \\
\hline 0 & $8 / 90$ & $\begin{array}{l}\text { Quality Assurance Program } \\
\text { Plan for the Hazardous Waste } \\
\text { Handling Facility (HWHF) }\end{array}$ \\
\hline 1 & $6 / 92$ & $\begin{array}{l}\text { Waste Management Quality } \\
\text { Assurance Implementing } \\
\text { Management Plan }\end{array}$ \\
\hline 2 & $11 / 93$ & $\begin{array}{l}\text { Rewrite of the LBNL Waste } \\
\text { Management Quality } \\
\text { Assurance Implementing } \\
\text { Management Plan, dated } \\
\text { 6/92. }\end{array}$ \\
\hline 3 & 10/12/99 & $\begin{array}{l}\text { Rewrite to update with current } \\
\text { practices and to integrate with } \\
\text { OAP, Rev. } 6 \text {. }\end{array}$ \\
\hline 4 & 3/29/02 & $\begin{array}{l}\text { Update references to current } \\
\text { OAP on Web; other minor } \\
\text { updates. }\end{array}$ \\
\hline 5 & $6 / 4 / 04$ & $\begin{array}{l}\text { Revise to update with current } \\
\text { practices. Change procedure- } \\
\text { review cycle to every four } \\
\text { years. Update Waste } \\
\text { Management group } \\
\text { organization chart. }\end{array}$ \\
\hline 6 & 8/14/06 & $\begin{array}{l}\text { Revised to update current } \\
\text { practices. New organization } \\
\text { chart, roles, and } \\
\text { responsibilities. }\end{array}$ \\
\hline
\end{tabular}




\section{Statement of Policy}

The Lawrence Berkeley National Laboratory (LBNL) Environment, Health and Safety (EH\&S) Division and the Waste Management Group (WMG) recognize and endorse the application of quality management and the value of a coordinated quality assurance management program. The WMG Quality Assurance Plan (QAP) provides the framework for ensuring control of the quality of WMG activities and those waste-related activities affecting Berkeley Lab.

Achieving quality within WMG is the responsibility of all personnel engaged in qualityaffecting activities. Verification of the achievement of quality within WMG is the responsibility of EH\&S’s Office of Contract Assurance (OCA) and WMG personnel. Full authority and organizational freedom are provided to identify quality concerns, recommend solutions, verify corrective actions, and stop work of unacceptable activities or practices that may adversely affect quality.

Management, at all levels in WMG, is responsible for quality, and believes a "no-fault" attitude encourages the identification of problems. We ensure that proper focus is given and adequate resources are provided for QA, and that all QA issues are resolved. We encourage all personnel to identify problems and offer solutions, and are committed to continuous quality improvement. We encourage all personnel to exceed the expectations of their customers whenever possible as a quality-improvement goal.

This plan identifies WMG quality-assurance activities and those actions taken to define quality-affecting activities and processes requiring the identification of specific documentation, reviews, hold points, and corrective actions. In addition, it is the policy of the Waste Management Group to identify hazards in our activities, plan the work to mitigate those hazards, use appropriate controls while doing the work, assess our performance after the work is completed, and incorporate lessons learned into our processes.

Nancy E. Rothermich

Waste Management Group Leader 


\section{Introduction}

The WMG QAP is an integral part of a management system designed to ensure that WMG activities are planned, performed, documented, and verified in a manner that assures a quality product. A quality product is one that meets all waste acceptance criteria, conforms to all permit and regulatory requirements, and is accepted at the offsite treatment, storage, and disposal facility. In addition to internal processes, this QA Plan identifies WMG processes providing oversight and assurance to line management that waste is managed according to all federal, state, and local requirements for waste generator areas.

A variety of quality assurance activities are integral to managing waste. These QA functions have been identified in the relevant procedures and in subsequent sections of this plan.

The WMG QAP defines the requirements of the WMG quality assurance program. These requirements are derived from Department of Energy (DOE) Order 414.1C, Quality Assurance, Contractor Requirements Document, the LBNL Operating and Assurance Program Plan (OAP, on the Web at http://www.lbl.gov/ehs/oap/oap_home.htm), and other applicable environmental compliance documents.

The QAP and all associated WMG policies and procedures are periodically reviewed and revised, as necessary, to implement corrective actions, and to reflect changes that have occurred in regulations, requirements, or practices as a result of feedback on work performed or lessons learned from other organizations.

The provisions of this QAP and its implementing documents apply to quality-affecting activities performed by the WMG; WMG personnel, contractors, and vendors; and personnel from other associated LBNL organizations, except where such contractors, vendors, or organizations are governed by their own WMG-approved QA programs.

Reference documents used to prepare the QAP include:

- $\quad$ Waste Management Group Quality Assurance Plan (QAP) (LBNL/PUB-5352, latest revision)

- $\quad$ LBNL Operating and Assurance Program Plan (OAP) (LBNL/PUB-3111, current revision on the Web)

- Hazardous Waste Treatment and Storage Permit Application, Hazardous Waste Handling Facility (Part B Permit) (latest revision)

- $\quad$ Final Safety Analysis Document for the Hazardous Waste Handling Facility, Rev. 1 (FSAD) (latest revision)

- $\quad$ Radioactive Waste Management Basis for the Ernest Orlando Lawrence Berkeley National Laboratory, latest revision

- $\quad$ RWA 1149 (Radiological Work Authorization for the HWHF) 
- Hazardous Waste Handling Facility Health and Safety Plan, latest revision 


\subsection{Program}

\subsection{Organizational Structure}

The WMG developed this QAP as the written description of the WMG quality assurance program. The figure below shows the current Waste Management Group organization chart.

\section{EH\&S Waste Management Group Organization Chart}

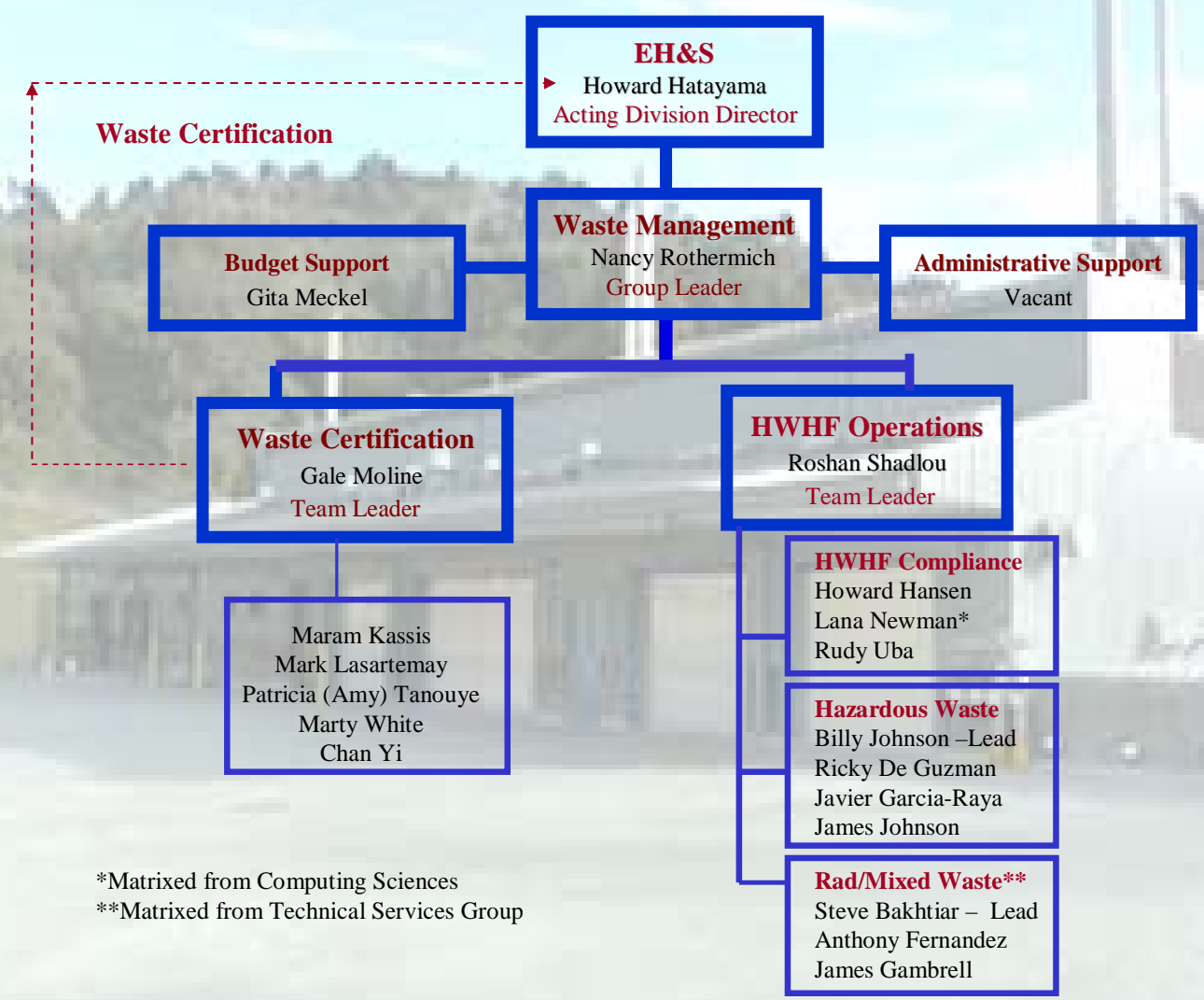




\subsection{Management Quality Assurance Functions}

The functions and responsibilities of WMG managers and selected other positions at LBNL that have direct responsibility for ensuring the quality of internal WMG activities and Berkeley Lab waste-related functions are described below:

The EH\&S Division Director has overall responsibility for the quality of work performed by the division.

The Waste Management Group Leader is responsible for the strategic direction of the organization, assuring that waste activities are planned, organized, managed, developed, implemented, and budgeted, and that line management who support and research activities are compliant with federal and state laws/regulations while ensuring minimal disruption to the Lab's programs. Program excellence is assured through contract performance measures and the Lab's self-assessment program.

The Hazardous Waste Handling Facility (HWHF) Operations Team Leader plans, directs, and manages the processing of universal, hazardous, radioactive, and mixed waste at the Hazardous Waste Handling Facility (HWHF), including waste collection, transportation, storage, labeling, sampling, treatment, consolidation, inventory, compaction, packaging, and shipment, and assures compliance of the HWHF with all DOE, federal, and state regulations and compliance orders.

The WMG Certification Team Leader serves as the Waste Certification Official and technical lead on all matters of waste characterization and transportation compliance; ensures wastes generated by Berkeley Lab’s research and support operations are described sufficiently to support compliant management on site, and to meet the waste acceptance criteria (WAC) of off-site Treatment, Storage, and Disposal Facilities (TSDFs); and is the Laboratory spokesperson for all waste certification issues with off-site TSDFs and other DOE sites.

WMG Staff are responsible for ensuring the highest-quality work, and for identifying, for management, potential problems where quality may be affected.

\subsection{Planning}

QA requirements to WMG activities are applied in a comprehensive and systematic way. Therefore, QA-related WMG activities are planned and scheduled as early as practical and prior to the start of the activity, so that QA requirements may be adequately implemented.

Subcontractors, vendors, or other LBNL organizations that participate in WMG quality-affecting activities must develop and implement WMG-approved QA 
programs, or comply with the provisions of the WMG QAP and associated implementing procedures.

\subsection{Personnel Training and Qualification}

WMG personnel involved in quality-affecting activities must receive orientation and training to assure proper understanding of QA requirements prior to initiation of the activities. Specialized orientation and training measures must be provided to assure that personnel, including quality-verification personnel, achieve and maintain suitable proficiency in the activities they perform. Training must be provided in a timely manner prior to the performance of any functions or operations that depend on, or are related to, the training. The WM Group Leader or designee must assure that training needs are identified and that assigned staff receive complete training commensurate with the scope and complexity of their assigned tasks.

WMG supervisors and managers must perform the activities related to staff proficiency outlined in the "Organization" section ("Staff Proficiency" subsection) of the Operating and Assurance Plan (OAP). General WMG training and personnel qualification requirements are presented below.

\subsection{Orientation, Training, and Evaluation of Personnel}

Training for WMG personnel is provided in-house, by various LBNL departments, and by outside vendors and agencies through course work, seminars, conferences, and other educational opportunities. Some of these offerings are elective, and WMG personnel may attend such training whenever resources and time allow. Completion of training activities must be documented. Training may be provided in the form of required reading, formal classroom sessions, or other methods. On-the-job training, where required, must be documented. Periodic observation and assessments by WM Team Leaders are performed to evaluate performance. These assessments are documented.

Personnel that verify conformance of work activities must be qualified to perform the assigned inspection task. Personnel selected for assessments or other evaluations must collectively have training and experience commensurate with the scope and complexity of the activities to be evaluated. Individuals participating in a quality-verification activity must be independent of any direct responsibility for performance of the activities that they will evaluate. 


\section{$2.2 \quad$ Orientation and Training of Waste Generators}

LBNL waste is characterized primarily through process knowledge. To assure accurate process knowledge, LBNL personnel who generate waste must be adequately trained to ensure the quality of waste accumulation and characterization information. All waste generators receive the same initial training. Radioactive and mixed waste generators must take the initial training course for hazardous waste and an additional course for radioactive and mixed wastes. Waste generators are responsible for complying with the latest revision of PUB-3092, Guidelines for Generators to Meet HWHF Acceptance Requirements for Hazardous, Radioactive, and Mixed Wastes at Berkeley Lab (http://www.lbl.gov/ehs/waste/wm_pub_3092.shtml). To assure that generators meet the training requirements to characterize waste sufficiently for off-site disposal, waste is not accepted from generators who lack documented waste generator training. A one-time exception may be made to this requirement upon approval of the Waste Certification Official.

A separate additional training course is required for generators who manage 90day storage areas (called Waste Accumulation Areas, or WAAs). WAA refresher training is required annually. Other refresher training may be required if the generator receives a QA Exception Report [see Section 3.0], or if any other nonconformance is noted. Other classes are available on SAA management, medical waste generation, and waste generation for guest/visitors.

WM staff provide consultative support to waste generators on an ad hoc basis to assure waste is accurately described and managed in the generator areas.

Generator proficiency is verified continuously through evaluation of generator waste characterization and inspection, and assessment of Satellite Accumulation Areas (SAAs) and WAAs.

\subsection{Quality Improvement}

QA Exception Reporting. The WMG waste characterization QA program conducts random sampling of incoming generators' waste to verify generator waste characterization. QA Exception Reports are issued for inadequate characterization of wastes. The Certification Team Leader or designee investigates all QA exceptions. If the exception is resolved without need for further action, it is considered minor and is documented in the QA Exception Report binder. Major waste characterization or regulatory failures require issuance of a Nonconformance and Corrective Action Report (NCAR), described in procedures 817 and 808.

Tracking and Closure of NCARs. The WM Group Leader tracks the status of all NCARs from origination until closure. All responses to NCARs are evaluated to verify that all the requirements have been addressed. Upon approval of the proposed corrective action, the Generator Assistant verifies implementation of NCAR 
corrective action. Upon verification of implementation of corrective actions and the generation of the required records, the WM Group Leader closes the NCAR.

Trend Analysis. The WMG Leader must enter WMG QAP deficiencies into CATS for trend analysis. Trend analysis should include, but not be limited to, NCARs, assessment findings, and root-cause analysis. The ultimate purpose of this trend analysis is to proactively attempt to note trends that require a management response before the trend becomes an actual problem.

Segregation of Nonconforming Items. When the nonconforming condition involves a physical item (e.g., a defective piece of equipment), the item is segregated, when practical, by placing it in a clearly identified and designated hold area until properly handled. When segregation is impossible or impractical due to physical conditions, environmental conditions, size, weight, access limitations, or other such reasons, other precautions are taken to preclude inadvertent use of a nonconforming item. Such measures include tagging, flagging, securing, or posting security measures.

Lessons Learned. For infrequent or unusual activities, the WMG Leader or designee will conduct lessons-learned sessions where warranted. The session(s) are to include all involved parties, and are to identify areas of improvement and good performance and lessons learned for future activities. Areas of improvement may result in procedural or instructional changes.

Observation of Work. Periodic observation of routine activities identifies areas where procedures should be improved, and assures that employees are adhering to procedures and safety requirements. Results of these observations are fed back to the individuals, and improvements are made (as warranted) to procedures and safety.

Corrective Actions. Findings, concerns, and deficiencies identified in an assessment should be addressed immediately. If corrective action cannot be done on the spot, a corrective action plan should be prepared to allow for additional planning and scheduling. The tasks identified in a corrective action plan are tracked through CATS for assessments and institutional or divisional concerns. Corrective actions are tracked until completion and management verification.

To ensure effective corrective action and continuous improvement, the WMG Leader, with assistance from EH\&S and OCA, performs root-cause analysis and develops lessons-learned to prevent problems from recurring. Such activity is commensurate with the hazard, significance, and consequence of the problem. 


\subsection{Documents and Records}

Documents that specify QA requirements or prescribe quality-affecting activities are prepared; reviewed for adequacy, completeness, and correctness; and approved and released for issuance and distribution in accordance with written procedures.

\subsection{Operating Procedures}

WMG has various procedures addressing the operation of the HWHF. These are based on controls required by the Part B Permit, the FSAD, Health and Safety Plan, and the RWA. These include procedures limiting personnel access to the HWHF; inspection and verification of the operability and calibration of measuring and testing equipment; and inspection of the facility, safety systems, and equipment.

Procedures or instructions must be prepared at a level of detail that ensures that the activity can be performed as required by the appropriate personnel.

Procedures and instructions must include or refer to appropriate quantitative or qualitative acceptance criteria for determining that prescribed activities have been completed as specified. Procedures and instructions must be uniquely identifiable, retrievable, and reproducible.

\subsubsection{Preparation of Written Procedures, Work Plans, Instructions, and Reports}

Quality-affecting core functions and facility-specific functions conducted by WMG are detailed in formal written procedures. All WMG procedures are identified in the WMG Master Procedure List.

The preparation and review of procedures, work plans, instructions, reports, and other documents must address, as a minimum, the following requirements:

- $\quad$ Identification of WMG personnel responsible for the preparation, review, approval, and issuance of the document.

- $\quad$ Review by individuals with responsibility for implementation.

- $\quad$ Review by individuals other than the author of the document.

- $\quad$ Sufficient access by the reviewers to pertinent background data.

- $\quad$ Resolution of review comments.

- $\quad$ Management resolution of unresolved issues. 
- $\quad$ Review and approval of changes by the same organization that performed the original review and approval.

Procedures must be formatted to include the requirements as appropriate and as specified in EH\&S Procedure 805 (latest revision).

Approved procedures must be issued through the document control process identified in the "Process Management" section ("Records" subsection) of the OAP.

\subsubsection{Procedure Review and Revision Process}

Procedures and instructions must be reviewed for applicable technical and administrative details. Each procedure must be reviewed for accuracy at least once every four years; however, most procedures undergo more frequent changes as operations are modified and lessons-learned are incorporated. These changes fall into three categories: major, minor, and on the spot. These categories are described in Procedure 805.

Revisions to procedures and instructions must be controlled by the same process used to review and approve the original procedures or instructions.

\subsubsection{Control of Formal Procedures and Documentation Binder}

The WMG Documentation binder is a controlled collection of reference documents important to quality-affecting activities. Control of documents involves distributing revisions to individuals and assuring that the latest documents are available prior to commencing work. Each WM Group member is responsible for the maintenance and upkeep of their assigned Procedure Manual and Documentation binder.

\subsection{Operating and Programmatic Records}

Specific record-keeping requirements are identified in the Part B Permit and RWA.

Much of the operating record is contained in the waste management database, ShoeBox. ShoeBox is an internally developed, Oracle-based system that assists the WM Group in compliance with waste-tracking activities required by the Part B permit. ShoeBox incorporates established business rules, and QA checks on data fields to assure accuracy of waste data.

Programmatic and operating records are identified by the procedure in which they are created. Operating Records are those records auditable by a regulatory agency to determine regulatory compliance. Records retained in the WM Operating Record must be retained in an organized file system so that the records are protected and easily accessible when needed. All records created by 
this procedure are kept in the WM Operating Record for three calendar years after their creation. After three years, they must be transferred to the LBNL Archives and Records Office as described in the LBNL Records Management Handbook.

Programmatic records are not Operating records and are created to document WM activities. All programmatic records created by a procedure may be kept in the WM Programmatic Record for three calendar years after their creation.

After

three years, they must be transferred to the LBNL Archives and Records Office as described in the LBNL Records Management Handbook. Some programmatic records are discarded after use.

A list of programmatic and operating records can be found on the G: drive in the WM folder, Procedure Records, Governing Documents, and References.

\subsection{Work Processes}

For all WMG core functions and other significant activities, WMG line managers must implement an integrated safety management process to ensure that safetyrelated work issues have been addressed comprehensively. At a minimum, line management must have auditable evidence of the identification and control of hazards in their responsible workplaces. WMG addresses routine hazards in the workplace through the maintenance of the Final Safety Analysis Document for the Hazardous Waste Handling Facility (FSAD), Radioactive Work Authorization (RWA), the Hazardous Waste Treatment and Storage Permit Application for the Hazardous Waste Handling Facility (the Part B Permit), and the HWHF Health and Safety Plan. These documents address potential hazards and the engineering controls needed to mitigate these hazards. WMG procedures incorporate the safety requirements from these four documents for routine activities. Specific project work plans are developed for nonroutine activities and address project-specific hazards and their mitigation.

\subsection{General Controls}

The basic functions of the WMG include waste generator interface, waste pickups, waste storage, waste sampling, waste shipments, and inspections of the HWHF and WAAs. These functions are controlled by WM procedures that employ the following general controls:

- $\quad$ Checkpoints in the process where management review and approval are required.

- $\quad$ Use of safety standards and requirements necessary and sufficient to mitigate the hazards of the work process. 
- $\quad$ Assurance that only qualified and trained personnel are assigned to perform the work.

- Assurance that only the appropriate equipment and materials are used.

- $\quad$ Assurance that up-to-date written procedures to direct the work are being used.

- Acceptance criteria for final review of end product or service.

\subsection{Data Collection}

WMG follows the guidance for data collection contained in the "Process Management" ("Control—Data Collection" subsection) of the OAP and the following additional guidance for collection of samples for waste verification.

Samples are identified and controlled in a manner that complies with regulatory guidelines and industry standards, and provides traceability for all associated sampling documentation (e.g., chain-of-custody). Methods for collecting, handling, transporting, and storing samples are described in EH\&S Procedure 817.

The procedure identifies the required protocols to assure the technical validity, safety, and environmental conditions to avoid degradation. Requirements for offsite transportation are in accordance with local, state, and federal regulations. Special handling requirements and traceability between organizations are also described in EH\&S Procedure 817.

Data from certified analytical labs are electronically delivered to the wastetracking system, ShoeBox, where they are assessed to assure all data are present. The electronic and/or hard copy of the analysis is reviewed by staff to corroborate or refute the generator's characterization.

Any limitations on data use are identified quantitatively and fully documented in the analysis report. Reports containing data are peer-reviewed by WM personnel to confirm that the data or results are presented correctly. 


\subsection{Design}

WMG does not design, or cause to be designed, any item of hardware that supports a quality-affecting activity.

WMG designed the software for the current waste-tracking system, ShoeBox. This system is described, maintained, and modified by internal computer-development staff. The system is designed to meet all waste-tracking requirements of the Hazardous Waste Treatment and Storage Permit Application for the Hazardous Waste Handling Facility (the Part B Permit) and internal system-development standards and criteria. Periodic modifications are made to incorporate new requirements or process improvements, and are thoroughly tested prior to implementation.

\subsection{Procurement}

WMG follows the guidance for procurement contained in the "Process Management" ("Process Control-Procurement" subsection) of the OAP.

WMG procures a variety of materials to support operations. All shipping containers must meet the appropriate DOT standards. Where these standards are required, they are specified in the appropriate procurement documents and verified on receipt.

\subsection{Inspection and Testing}

In accordance with applicable local, state, and federal regulations and the Part B Permit, the HWHF must be inspected on daily, weekly, and monthly bases, depending on the item(s) inspected. Records of these inspections are maintained, and any deficiencies noted are corrected and documented in a timely manner.

Waste generator satellite accumulation areas (SAAs) must be inspected periodically, during the course of regularly scheduled visits to these sites by WMG personnel. Waste Accumulation Areas (WAAs) must be inspected weekly. Any deficiencies noted in SAAs or WAAs must be corrected in a timely manner.

Containers used to ship waste must comply with appropriate DOT standards. EH\&S Procedure 822, Container Procurement, Receipt, Inspection, and Acceptance, identifies the methods for procuring, receiving, inspecting, accepting, and rejecting containers used for packaging low-level radioactive waste, mixed waste, and 
hazardous waste for storage at the HWHF and shipment to offsite treatment, storage, and disposal facilities.

Verification sampling is required of approximately $10 \%$ of all waste containers received at the HWHF. In addition, waste containers are inspected during pickup for labeling, and for compatible and appropriate packaging. Verification sampling may require a visual inspection or an aliquot sent to a certified analytical lab. Specific controls are identified in EH\&S Procedure 817.

The LBNL Facilities Operations and Maintenance Group is responsible for the HWHF facility maintenance. This includes the ventilation systems, backup generator, and other critical items. Scheduled preventive maintenance is tracked through the use of the Maximo computer tracking system.

Work orders are used to request nonroutine repair of HWHF systems. Records of these items are maintained at the Facilities Department offices.

\subsection{Management Assessment}

Self-Assessments. The adequacy and effectiveness of the QA program must be determined by conducting management assessments on an ongoing or periodic basis. The management assessment is performed to:

- Identify management problems that hinder the organization from achieving its objectives in accordance with quality, safety, and environmental requirements.

- Evaluate the effectiveness of controls that achieve and assure quality.

- Assess the adequacy of resources and personnel with respect to providing a quality program.

- Determine the effectiveness of personnel training.

The most common methods of performing management assessments are:

- Review of management reports (status reports, technical reports, etc.)

- Review of quality-verification reports (independent assessment reports, inspection reports, test reports, etc.)

- Review of corrective-action reports, including trend-analysis reports, on a regular basis

- Interviews with WMG personnel 
The WMG Leader retains overall responsibility for management assessments. Management assessment results must be documented. WMG management must take prompt action to correct any observed nonconformance, and must document decisions made and corrective actions taken.

WMG regularly evaluates and improves internal performance by

- Conducting observations of procedure implementation,

- Conducting lessons-learned from nonroutine projects,

- Correcting any performance deficiencies noted from the assessments, and

- Incorporating lessons-learned from internal or external performance.

\subsection{Independent Assessments}

LBNL's Office of Contract Assurance may perform independent assessments of WMG. The Office of Laboratory Counsel, for the purpose of providing legal advice to Laboratory management, periodically conducts nonroutine assessments of the WM facility and functions. 